\title{
MARKETS FOR REPUTATION: EVIDENCE ON QUALITY AND QUANTITY IN ACADEME
}

\author{
Daniel S. Hamermesh and Gerard A. Pfann*
}

* Sue Killam Professor in the Foundations of Economics, University of Texas at Austin, IZA and NBER; professor of econometrics and organization, Maastricht University, CEPR and IZA. We thank Randall Akee, Kenneth Hendricks, Andrea Ichino, Lawrence Kahn, Arthur Markman, James Pennebaker, James Ragan, Joe Stone, Mark Walker, and participants in seminars at several universities and the IZA. Karen Mulligan and Amanda Smith provided very careful research assistance. 


\begin{abstract}
We examine the determinants of reputation, an indicator of regard by one's peers. The central questions are: 1) Does the quantity of exposures raise reputation independent of their quality? and 2) Assuming that their overall quality matters for reputation, does the quality of an individual's most important exposure have an extra effect on reputation? Using evidence for academic economists, we find that, conditional on its impact, the quantity of output has no or even a negative impact on each of a number of proxies for reputation, and at most weak evidence that a scholar's most influential work provides any extra enhancement of reputation. Data on salaries show, on the contrary, substantial positive effects of quantity, independent of quality. Quality ranking matters more than does absolute quality. The results suggest that in the market for reputation one is judged solely by quality, but that salary is determined in surprisingly different ways from reputation.
\end{abstract}

Keywords: quality/quantity trade-off; memory; salary determination

JEL Codes: L14; J31 


\section{Introduction}

There has been an immense literature in economics on the formation of reputation, both of individuals and of the groups to which they belong. Most of the research has been purely theoretical, with much of the work focused on reputation arising from behavior in repeated games (see Mailath and Samuelson, 2006). Another strand of theory has focused on timing, including the dynamics of the relation of individuals' behavior and reputations and those of the firms for which they work (or the products or services they produce) (Tirole, 1996) and on the reputation-maximizing timing of the release of information (Sarafidis, 2007). Presumably reputation, defined as "overall quality or character as seen or judged by people in general," is something that develops over time in the minds of those who are judging the person, group, product, etc. ${ }^{1}$

Because reputation is based on perceptions of "overall quality," the appropriate prior question would seem to be what we mean by quality - what aspects of individuals' behavior contribute to quality and thus generate their reputations and those of the groups to which they belong. As such, the construction of reputation might be thought of as analogous to an implicit market in which bundled aspects of a good or service are traded for some overall price (Rosen, 1974). A "supplier" of characteristics brings them to a market, where "purchasers" (employers; the public; one's professional peers; one's fellow employees; one's neighbors; one's customers) express their preferences by assigning reputations to the suppliers. These reputations in turn produce higher monetary and/or non-monetary rewards for the person to whom they are attached. In this implicit market for reputation the returns to its various determinants are created by the buyers' preferences and the ability of existing and potential suppliers to generate those determinants. We can always measure the market "price" of the dimensions of quality; and if we can identify the separate behavior of each party, or assume that one party's behavior does not respond to the returns to various aspects of quality, we can even infer the structure of preferences for reputational quality and/or the reputation-enhancing productivity of various characteristics.

\footnotetext{
${ }^{1}$ Merriam-Webster Online Dictionary, June 5, 2008.
} 
In this study we concentrate on the example of the determinants of the reputations of academic economists. Our particular focus is on how the market values both the quantity of their scholarly output and, in the spirit of the hedonic markets literature, various aspects of the quality of their output. The more specific questions are: 1) How does the quantity of publications affect the regard in which a scholar is held by his/her colleagues? 2) Do a few extremely well-regarded publications have the same reputational effect as an equally successful (in terms of its total impact on other scholars) publication list that is more diffuse? and 3) Are the determinants of reputation the same as the determinants of pecuniary returns? The answers to these specific questions about the rewards to scholars should shed some light on the general determinants of reputation, especially about how its formation is affected by the trade-offs along various dimensions of reputation-enhancing activities, as well as on the pecuniary returns to reputation.

\section{Thinking about Reputation}

Our question is about how reputation is formed - what goes on in buyers' minds as they observe the outcomes of suppliers' efforts that might generate reputations. Presumably reputation is related to memory and how the actions and sequences of suppliers' behavior produce memories in the minds of the buyers. As such, the literature on memory and learning in experimental psychology may be informative for our purposes. That literature unsurprisingly makes it clear that memory is enhanced by additional exposure. In terms of our question about the trade-offs among the dimensions of quality, however, the issue is whether memory of an item within a class is better enhanced by a given number of stimuli of one item in that class or of several different items in the class.

The fundamental work in the general area (Tulving and Thomson, 1973) demonstrated the complexities of memory and proposed a theory of "encoding specificity"- that the specifics underlying exposure to events and the keys that might lead to the retrieval of memory interact to determine how memories develop. This study led to a huge literature, none of which speaks directly to our question; but there are several recent studies that shed some light on it. Arnold and Lindsay (2002) imply that people will remember better if they are stimulated by exact repetition of the event rather than by variations in it. Starns and Hicks (2005) show that providing related stimuli at the same time has complementary effects on memory of each, but that this is only true if the stimuli are provided in the same learning session. In a 
slightly different context, the results of Kurtz and Loewenstein (2007) seem similar. Overall one might infer that these experiments support the notion that memory will be more strongly enhanced by repetitions of the same stimulus than by the same number of different, but related stimuli (implying perhaps for our purposes that scholarly reputation may be more strongly affected by a very important publication than by a series of less important works).

While there are many human endeavors in which multiple dimensions of quality might be viewed as determining rewards, there has heretofore been no direct analysis of the relative roles of different measures of quality. One area in which one might examine such effects is in sports, with the most research having been carried out on major league baseball. While no studies have focused on our concerns, several have examined salary determination as affected by various dimensions of players' productivity. Faurot and McAllister (1992) find a negative effect of home runs on arbitrators' salary awards, once runs created are held constant; Kahn's (1993) estimates of salary determination do not suggest any additional effects of extra-base hits on salary among white batters. At least in the endeavor of professional baseball a second dimension of quality does not appear to generate additional rewards beyond those produced by overall quality.

Our particular issue is how the market reward structure for reputation, $\mathrm{R}$, is affected by three dimensions of production: Quantity, and two types of quality. ${ }^{2}$ In the example of academic reputation, we define quantity as the number of publications, $\mathrm{Q}$. We define quality as $\mathrm{q}_{1}$, the total recognition of a scholar's entire oeuvre by other scholars, and $\mathrm{q}_{2 \mathrm{n}}$, the recognition of his/her n'th-most recognized publication (where $\mathrm{n}$ is some arbitrary small number, with $\mathrm{n}=1$ in most of our empirical work). ${ }^{3} \mathrm{We}$ assume that the scholar's profession offers rewards based on reputation. Buyers i thus have some demand for reputation as a function of these characteristics:

(1) $\quad \mathrm{R}_{\mathrm{i}}^{\mathrm{D}}=\mathrm{R}_{\mathrm{i}}^{\mathrm{D}}\left(\mathrm{Q}, \mathrm{q}_{1}, \mathrm{q}_{2 \mathrm{n}}\right)$,

\footnotetext{
${ }^{2}$ Obviously we could generalize this to additional dimensions of quality; but the formulation we use is the simplest that allows us to construct empirical analogues.

${ }^{3}$ One might for convenience analogize to baseball and think of $\mathrm{Q}$ as at-bats, $\mathrm{q}_{1}$ as runs batted in and $\mathrm{q}_{21}$ as slugging average.
} 
with the partial derivatives $\mathrm{R}^{\mathrm{D}}{ }_{\mathrm{ij}} \geq 0$ for all $\mathrm{j}$ dimensions of reputation-enhancing activity. The responses of reputation to its determinants show the marginal willingness of demanders to reward various dimensions of scholarly work.

The identity of the "buyers" of reputation varies with the example. Certainly the phrase from the definition, "people in general," should not be interpreted too broadly. The public in general does not determine (and probably does not care) about the reputations of individual scholars. Also, within the scholarly community some members undoubtedly have a greater influence in contributing to judgments about reputations than do others. Because of the difficulties in identifying members of the groups that determine reputation, we base our example on a wide variety of measures of reputation. The buyers could be the individual's professional peers, his/her professional organization, some professional opinion leaders, or perhaps those institutions that are potential or actual buyers of his/her services.

By analogy, the scholars whose reputations are determined in this market generally engage in activities that will maximize their reputations (and thus the returns to their activities), conditional on their abilities, by responding to the market returns to quantity and the quality dimensions. Their activities will produce an analogous set of reputational supply functions, one by each of the $\mathrm{K}$ scholar/participants in this reputational market:

$$
\mathrm{R}_{\mathrm{k}}^{\mathrm{S}}=\mathrm{R}_{\mathrm{k}}^{\mathrm{S}}\left(\mathrm{Q}, \mathrm{q}_{1}, \mathrm{q}_{2 \mathrm{n}}\right)
$$

with the $\mathrm{R}_{\mathrm{kj}}^{\mathrm{S}} \geq 0$ for all $\mathrm{j}$. The responses in (2) show the reputational returns to an increase in particular aspects of a scholar's efforts. As is usual in hedonic models, together the demand and supply functions interact to generate a market reward function describing the determinants of reputation:

$$
R=R\left(Q, q_{1}, q_{2 n}\right) \text {, with } R_{j} \geq 0 \text { for all } j .
$$

The buyers i presumably differ in their ability to purchase reputation- those institutions that are richer will be able to buy more reputation, and in general will presumably be observed with a staff that has higher $\mathrm{Q}, \mathrm{q}_{1}$ and $\mathrm{q}_{2 \mathrm{n}}$. There is no reason to assume that the $\mathrm{R}^{\mathrm{D}}{ }_{\mathrm{i}}$ are homothetic, so that an interesting empirical exercise would try to examine how the returns to these determinants of reputation vary with the 
total resources available to the buyers to purchase reputation. ${ }^{4}$ Whether there is any substitution in scholars' production of reputation and whether the supply functions (2) actually result from some maximizing calculations are more difficult questions: If the returns to particular dimensions of quality differ, are scholars aware of this? Even if they are aware, and assuming that they seek to maximize their reputations, are they capable of substituting toward more highly rewarded dimensions? It may well be that each scholar has a Leontief-type production function in these inputs (although clearly individual production functions may differ) so that no supply-side substitution is possible.

\section{Testing the Determinants of Reputation-Measuring Inputs and Outputs}

\section{A. General Issues}

Ideally we would have measures of individuals' reputations or of some result of the reputations that they have established. One approach is based on the notion that some of the purchasers of reputation are one's peers, so that awards conferred by peers represent their assessments of a scholar's reputation. A second approach assumes that the members of an academic collective (department) seek to avoid diminishing the collective's reputation. To accomplish this they only add those marginal members whose individual reputations are at least as high as some summary measure of the reputations of the collective's current members (e.g., Rosen, 1987; Basu, 1989, and, by analogy, the literature on the worker-managed firm going back to Ward, 1958). ${ }^{5}$ Thus for members of collectives that are sufficiently large, a measure of individual reputation is the average reputation of the collective. Taking the same tack, the collective's reputation is an even better proxy for the reputations of its newer members - those whose reputations were recently deemed by more senior members of the collective to be sufficiently high so as not to reduce the collective's reputation.

\footnotetext{
${ }^{4}$ This view of buyers seeking to purchase reputation based on their resources predicts the relatively unsurprising result that scholars attached to richer schools will have greater reputations. This outcome arises not because the school confers reputation on the scholar, but rather because it can "purchase" the services of those scholars who are capable of generating greater reputations for themselves, which are then conferred onto the institution. This approach has the interesting prediction that, where there is greater heterogeneity in institutional resources, we should observe a steeper gradient across institutions in the extent of scholarly reputation. This prediction seems supported by work of Cardoso et al (2008) showing that the research success of younger American labor economists varies more with the source of their doctorate than does that of their European counterparts.

${ }^{5}$ The minimum size of the collective for this purpose is not clear, and in the empirical work we experiment with various cut-offs.
} 
One might argue that salary or compensation is a result of scholarly reputation and can be analyzed in the same way as the indicators already discussed. Since we assume that economics departments and the universities of which they are constituents attempt to maximize reputation, one might even expect that the inputs that affect reputation will affect salaries in similar ways. Indeed, a long literature exists in economics on the role of the quantity and quality of publications in salary determination, with citations by other scholars being the usual proxy for quality (Hamermesh et al, 1982; Moore et al, 1998; and Bratsberg et al, 2009, are just a few) and with counts of articles and books proxying quantity. This literature could be viewed as measuring the impacts of these indicators on an outcome of reputation. One way of obtaining extra salary is by obtaining additional job offers. These too are presumably based on one's reputation, so that examining a sub-sample of offers (accepted offers by job-changers) provides an additional test for the role of reputation and the possible distinction between its determinants and those of salaries.

\section{B. Specific Measures}

Our sample consists of full professors in those economics departments that are included among the 88 American departments that are listed as being in the top 200 in the world by Kalaitzidakis et al (2003). This provides a sample of 1350 scholars. While this sample is obviously selected - its members had to have sufficient individual reputations to be included in this fairly elite group of institutions - there is presumably enough variation in reputation across the 88 departments that selectivity bias is not solely responsible for any results we obtain. ${ }^{6}$

To proxy individual reputation we develop specific representations of the general measures outlined above. The first series of measures proxies reputation by awards received by the individual. We first define Honored as equaling one for those sample members who received a Nobel Prize, were elected President of the American Economic Association (AEA), named a Distinguished Fellow of the AEA or received its Clark Medal (awarded biennially to an economist under age 40). The set of individuals who are the buyers of reputation in (1) is the Nobel Committee (with solicited advice) for the Nobel Prize and various AEA committees for the other awards.

\footnotetext{
${ }^{6}$ In the Kalaitzidakis et al (2003) rankings these 88 departments range from Harvard to the University of Arkansas-Fayetteville in this selected group of institutions.
} 
The difficulty with Honored is that economists are extremely stingy in providing distinctions to each other- using this definition, an honor is received by only a tiny fraction of individuals even in this elite sample. A more broadly received indicator of reputation is election as a Fellow of the Econometric Society. (A description of the election procedures and a discussion of the determinants of fellowship are in Hamermesh and Schmidt, 2003.) Members of our sample account for all of the fellows who are not emeriti in American economics departments and for nearly half of all fellows world-wide. Here the buyers of reputation comprise the set of existing fellows.

The second series of measures is based on the reputation of the department with which the scholar is associated and stems from our hypothesis that the reputation-maximizing collective's reputation forms a lower bound of the individual's. The first measure is the department's ranking in Kalaitzidakis et al (2003) (between 1, the highest, and 200, the lowest). [This is the best measure currently available; but, because it is based on the quality of journals in which the departments' members published between 1995 and 1999, it has problems for our purposes. We will augment it in subsequent versions of this study by the subjective ratings of reputation compiled by the National Research Council in 2006, when they become available.] The National Research Council's (1995) subjective ratings of economic faculties in 1993 are another measure of departmental reputation. With them we examine the determinants of the collective reputations of the institutions to which scholars moved, implicitly therefore proxying the lower bounds of each scholar's reputation. ${ }^{7}$

Mobility itself is only possible for those scholars whose current reputations are, in this view of institutional behavior, at least equal to the collective reputation of a department that might hire them. That being the case, we create an indicator of whether a scholar moved between 1992 and 2007 (among those who had been professionally active at least since 1986, long enough to have established a reputation that might have affected their mobility). Salary data for individual faculty members are difficult to obtain (impossible for those at private institutions), but for 43 of the 53 public institutions in our sample we were able to acquire data from university websites and direct contacts to use to calculate full-time academic-

\footnotetext{
${ }^{7}$ Most department administrators are admonished to build a better department, one that is stronger in research. Thus, for example, one university describes the chair's role, "The chairperson has a special obligation to build a department strong in scholarship...." (Michigan State University, Faculty Handbook, 2.1.2.1)
} 
year salaries. ${ }^{8}$ After various consistency checks on these data we were left with usable observations on the academic-year salaries of 571 economists. $^{9}$

The measures of quantity and the dimensions of quality all come from the Social Science Citation Index, which includes articles in an immense variety of refereed and unrefereed journals, but no books or unpublished papers. ${ }^{10}$ Social science journals are where economists publish most of their scholarly work and are thus the outlets in which they establish their reputations and in which other scholars acknowledge their influence. ${ }^{11}$ To represent Q we take the number of different entries in a scholar's record from 19562007, a period that encompasses the active worklives of all members of our sample. The dimensions of quality are represented by citations, with $\mathrm{q}_{1}$ proxied by the total citations to a scholar's works that are included in $\mathrm{Q}$, and $\mathrm{q}_{2 \mathrm{n}}$ being the numbers of citations to the scholar's n'th most-cited work, $\mathrm{n}=1, \ldots, 5{ }^{12}$ Obtaining information for those whose names are unique (like the authors of this paper) is not difficult; for nearly 100 others it required direct comparisons of curricula vitae to the entries in the SSCI and, in

\footnotetext{
${ }^{8}$ Most of the data were for $2007-08$, but where they were not we used $1.04^{(2007-t)}$ to inflate salaries. One institution only had salary data for 2004-05, while for many, particularly the University of California system, the data were for 2006-07. In some cases it was impossible to determine if the faculty member was on a 9-month appointment, and those cases were not included in the analysis.
}

${ }^{9}$ Sixteen of the schools included here comprise the biennial survey of salaries reported for 2006-07 at http://www.eco.utexas.edu/faculty/Hamermesh/EcSalsPublicCleaned.xls . The correlation of the average salaries computed here for each school and the averages provided there is 0.89 , suggesting relatively little systematic measurement error in our compilation of salary data.

${ }^{10}$ One might be concerned that excluding publications that are in science journals, and also excluding citations from science journals, might bias our results. It is obviously true that this exclusion generates errors; but the errors are clearly small - in a random sample of 50 observations (chosen from a consecutive section of the alphabet) the correlation between citations in the SSCI and total citations in the SSCI, Science Citation and Arts and Humanities Indexes together was 0.979 , while that between citations to the most-cited paper from the two sources was 0.993 . One might also be worried that we count all citations, including self-citations. To examine this potential problem we took another random sample of 50 and computed the correlation of total citations and total citations without selfcitations. The Pearsonian correlation coefficient was 0.984 , while the rank correlation coefficient was 0.991 . We thus do not view this as a problem. (In any case, while it is easy to obtain total citations excluding self-citations, obtaining $\mathrm{q}_{2 \mathrm{n}}$ excluding self-citations is not feasible.)

${ }^{11}$ This choice seems the best among the possible ways of counting total citations and citations to individual works.
One should stress, however, that Q, and thus the publications that could be cited, excludes books and working
papers. The former exclusion is not important for most economists, and the latter exclusion matters little in a sample
of full professors. The alternative use of the SSCI would be based on authors rather than publications, but the SSCI
does not allow a convenient tabulation of a scholar's most-cited works by this method. An alternative would be to
use Google Scholar or SCOPUS, but their methods of tabulation are less clear.

${ }^{12}$ The results of Cole and Cole (1973) make it clear that concerns that citations might measure infamy rather than fame are misplaced. 
several cases, correspondence with individuals in the sample. ${ }^{13}$

The other measures account for individual characteristics that may affect the measured market prices of the determinants of reputation because they may be correlated with either Q or one of the q. We include the year of the author's first publication listed in the SSCI to measure the time s/he has had to construct a reputation. The gender of the scholar may bias our measures of quality, since some have argued (Ferber, 1986) that same-sex citation is a common practice, (although others (Hamermesh and Schmidt, 2003) fail to find any disparate impact in a receipt of a particular award). The author's place in the alphabetical list in the sample may function similarly, as some (Einav and Yariv, 2006) have shown that those whose names are earlier in the alphabet tend to be favored in certain aspects of scholarly work. Finally, we used on-line vitae to generate a measure of whether the person received his/her undergraduate education at an English-language university, on the grounds that migration to the U.S. from the upper tail of the ability distribution might occur (Borjas, 1987) and might be correlated with the quantity and quality measures.

\section{Descriptive Statistics}

Table 1 presents statistics describing the outcome measures that we use to proxy reputation. The reputational ranking (again, 1 is highest) has a mean well below the average of 200 departments, partly because higher-ranked departments are larger, partly because American economics departments disproportionately comprise the higher ranks of the world-wide set of 200 institutions. The NRC ratings (with 5 being the maximum possible) indicate similarly that the average sample member's location is in a department that is fairly highly rated. Being Honored by the Nobel Committee or the AEA has been attained by only 3 percent of the full professors at these 88 departments, with honors, as we have defined them, having been received by individuals in only 18 different departments. Econometric Society Fellows comprise 20 percent of the sample and are found in 46 of the departments.

Table 2 contains information on the determinants of reputation that we use in our estimation. The first thing to notice about these inputs is the skewness of both quality measures - the means of both $\mathrm{q}_{1}$ and

\footnotetext{
${ }^{13}$ One might argue that citations themselves measure reputation. That argument, however, is equivalent to stating that labor inputs into production represent output. Given that we have various measures of reputation, it makes sense to view the process of reputation formation as citations, an input, producing one of our proxies for reputation, an output.
} 
the $\mathrm{q}_{2 \mathrm{n}}$ far exceed their medians; and the maxima are huge. The quantity measure is also highly skewed, although not nearly so much as the quality measures. We account for the distributions of all three measures in our estimation. In this sample 6 percent of the members are women, roughly consistent with a recent survey (CSWEP, 2007) showing 8.3 percent females among full professors at American Ph.D.granting institutions. Nearly one-fourth of the sample members received their undergraduate education in a country where English is not the predominant language.

Our central focus is on the role of dimensions of quality in determining reputation. If the quality measures were perfectly correlated, this would be a futile exercise. They are not, as the data shown in the left-hand columns of Table 3 on the top 20 economists demonstrate along two of the dimensions of q. Twelve of the twenty most heavily cited members of our sample are among the top twenty in terms of the scholar's most-cited single publication; and the median $\mathrm{q}_{21}$ of the other eight is 835 , close to the cut-off among the twenty scholars in Column (2). Obviously this information is barely more than anecdotal; and while the correlation of these two measures is high, 0.81 , the measures are far from perfectly collinear, suggesting there may be enough independent variation to allow us to examine the roles of both dimensions of quality in generating reputation.

While there is a high correlation between $\mathrm{q}_{1}$ and $\mathrm{q}_{21}$, their correlations with the number of items published are much lower- 0.56 for $\mathrm{q}_{1}, 0.32$ for $\mathrm{q}_{21}$. The final columns in Table 3 list the twenty authors with the most entries in the SSCI. Only four of these names appear on either of the other two lists in the table. The medians of $\mathrm{q}_{1}$ and $\mathrm{q}_{21}$ among the other sixteen most-frequent authors are 1561 and 114 , far above the sample medians, but also far below the cut-offs for the other columns in the table. Clearly, publishing papers represents a different dimension of activity from total measured quality or the quality of one's best-known work as indicated by citation counts.

\section{Estimating the Impact of Quantity and Qualities on Reputation}

\section{A. Reputation Reflected in Awards}

The first three columns of Table 4 report the results of estimating the impacts of $Q, \mathrm{q}_{1}$ and $\mathrm{q}_{21}$ on the probability of receiving one of the rare honors available to American economists. The second three columns present estimates of the determinants of having been elected a Fellow of the Econometric 
Society. In addition to the results displayed in the table the probits describing Honored all hold constant for alphabetical location and the year the scholar's first SSCI-indexed paper appeared, while the probits for election as Fellow add the indicator for female to these. ${ }^{14}$ Place in the alphabet never has a significant effect on receipt of one of these awards (and has no significant effect on any of the reputational measures discussed in this Section), nor does gender. Not surprisingly, being Honored is substantially more likely among authors whose first published paper appeared earlier - except for the Clark Medal these awards are usually for a lifetime of construction of reputation.

The results presented in Column (4) are similar to those in Column (1), as are those in Column (5) to Column (2), and Column (6) to Column (3). The first point to note throughout is that the number of entries, Q, never has a significant impact on reputation as measured in these two ways. Conditional on quality, having produced a lot of material adds nothing to reputation. Indeed, the effect on Fellow is negative and significant in two of the specifications. At the very least we can conclude that quantity does not matter for these proxies for academic distinction. ${ }^{15}$

There is some evidence in Table 4 that both dimensions of quality generate reputation, as proxied by these measures, although the returns to $\mathrm{q}_{21}$, conditional on $\mathrm{q}_{1}$, are not statistically significant. There is also evidence that the marginal payoff to additional citations in total, or to the author's most-cited work, is diminishing: Adding quadratic terms to these probits, as shown in Columns (2) and (5), substantially increases their ability to predict the receipt of these awards. ${ }^{16}$

Also intriguing in Table 4 are the changes in the estimates that occur when we recognize that, except for the Nobel Prize, each of the other honors is awarded to American economists on a regular

\footnotetext{
${ }^{14}$ The indicator for female is not included in these probits, because only one woman has been honored according to this measure.

${ }^{15}$ One might be concerned that we measure from the stock of existing Fellows, not from the flow of newly-elected Fellows. To do that would require obtaining information on Fellows at the time they were elected, which is difficult but possible. Fatally, however, it would require information on those who were never elected, most of whom were never on the Fellows ballot. While using the stock may introduce errors, there is no reason for them to be generating biases that lead these results to mirror those for all the other measures of reputation discussed in this Section.

${ }^{16}$ We do not use the h-index (Hirsch, 2005). (Ranking an author's papers in descending order of their citation counts, an author's $h$-value indexes the paper that is ranked $h$ 'th in the order and that receives $h$ citations. An h-index of around 35 is typical for Nobel laureates in economics.) For analytical purposes this measure has the problems that it combines quantity and quality and also fails to indicate dispersion in quality. No doubt it could be used here, but interpreting the meaning of any measured impact would be difficult.
} 
basis. Even if $\mathrm{Q}$ or each measure $\mathrm{q}$ were smaller, some American economist would have his/her reputation acknowledged by receipt of one of the AEA awards; and while it is not necessary, one might imagine that current Econometric Society Fellows, of whom half are Americans, would continue to elect many of their American peers. Columns (3) and (6) are identical to Columns (1) and (4), except that total citations, citations to the most-cited paper and number of publications are replaced by the scholar's rank along each dimension (with 1 being the highest rank). In the case of Honored the equation does not fit as well as the quadratic version, but the fit is better than in Column (1). The ability to predict receipt of election as Fellow is, however, substantially enhanced. ${ }^{17}$ These results suggest that the market for reputation, at least as proxied by these awards, may be more like a tournament than a competition in which additional quality per se increases the chance of success (Lazear and Rosen, 1981).

\section{B. Individual Reputation Reflected by Departmental Reputation}

In this sub-section we examine how the reputation of the economics department with which an individual is affiliated is related to the quantity and quality measures that we believe may determine reputation. We have argued that the market for scholars makes the reputation of one's department a proxy for one's own reputation and thus a reflection of the roles of quantity and quality of research in generating reputation. In order to maintain the assumption that a department of a given reputation is "purchasing" scholars' attributes, we arbitrarily restrict the samples in this section to departments with at least 10 full professors (so that presumably an individual's reputation has only a small part in establishing the reputation of the collective and reverse causation is avoided). This reduces the number of observations from 1350 to 1197 (and the number of departments to 66 ). ${ }^{18}$

The determinants of the scholarly reputation of the scholars (proxied by the reputation of their departments) are presented in Table 5. Included in all the equations but not shown in the table are the effects of alphabetical position and gender, neither of which came close to statistical significance in any of the estimates. Given the importance of size, the number of full professors in a department is held

\footnotetext{
${ }^{17}$ The equations in Columns (1)-(3) were re-estimated defining the outcome to exclude receipt of the Clark Medal. The results were very similar to those presented in the Table.

${ }^{18}$ The crucial results in this sub-section hardly change if we restrict the sub-sample to the 946 scholars located in the 44 departments with at least 15 full professors, or if we include all 1350 observations.
} 
constant and is unsurprisingly highly significant in increasing a department's reputation. Column (1) presents results analogous to those in Columns (1) and (4) of Table 4, except that here we also present the estimated effect of the year of the scholar's first SSCI-indexed paper. The estimates show that younger authors (those whose first papers are more recent) are associated with departments with higher reputational rankings. Holding this measure constant may be important and may reflect the crucial nature of one's first publication (Siow, 1991); but the result is at least partly an artifact of the sample selection criterion we have used - full professors. Those scholars who become full professors earlier tend to be associated with schools with higher reputations. ${ }^{19}$ This outcome may result from higher-ranked schools having sufficient resources to buy an option by gambling on very promising younger researchers.

Having been educated in an English-speaking country (for the overwhelming majority of the sample this is the U.S.) is associated with being at an institution with a lower reputation. This is similar to the results for election as Fellow, although having been educated abroad had no impact on being Honored by the Nobel Committee or the AEA. On the supply side these results may reflect self-selection by potential scholars from the upper tail of ability among potential non-American graduate students and/or faculty. On the demand side it may reflect the unwillingness of lower-ranked institutions to hire otherwise identical foreigners, either because they value teaching relatively more and are concerned about language ability, or because of pure discrimination.

As with the results on reputation reflected in awards, at the very least here too Q has no impact. The estimates in Column (1) of Table 5 show, however, that increases in both $\mathrm{q}_{1}$ and $\mathrm{q}_{21}$ lead the scholar to be located in a higher-ranked department, although both effects are only marginally significant statistically. When we allow for non-constant marginal returns to the quality measures, in the estimates shown in Column (2), it is clear that there are diminishing returns to quality along both dimensions. Moreover, both linear and quadratic terms along each quality dimension are statistically significant. Implicitly, the results demonstrate that higher-ranked departments are concerned with the quality of publications, as measured by the author's total recognition by other scholars, but also as proxied by the

\footnotetext{
${ }^{19}$ Dropping this measure from the regression does not greatly change the result: The coefficient on $\mathrm{q}_{1}$ becomes -0.480 and that on $\mathrm{q}_{21}$ becomes -1.105 .
} 
distinction of the scholar's best-known work. ${ }^{20}$ They do not, however, pay any attention to the quantity of publications.

Unlike the results in the previous sub-section, there is no mechanical reason to expect any relation between a scholar's rank along some quality dimension and his/her reputation, as reflected in the department with which s/he is affiliated. Departments and universities are, however, competing for prestige/students/funds, so that at least to some extent one might imagine that there are tournament-like aspects to the market for individuals' reputations as reflected in the ranking of their departments. To examine this possibility we re-estimated the basic equation, again proxying $\mathrm{Q}, \mathrm{q}_{1}$ and $\mathrm{q}_{21}$ by the scholar's rank in the sample along the criteria of number of publications, total citations and citations to his/her most-cited work. Comparing the results, presented in Column (3), to those in either of Columns (1) or (2), it is clear that a scholar's rank along all three measures has a bigger impact on his/her reputation than do the numerical equivalents. In this formulation, however, $\mathrm{q}_{21}$ is not important —only total citations matter. Moreover, the impact of one's rank in Q is negative; as with election as a Fellow, being among the more prolific scholars, conditional on the recognition one's work has received, reduces the reputation of the institution that has chosen to employ the scholar. While not explicitly a tournament for reputation, the results suggest that the market for scholarly reputation too has tournament-like characteristics along one dimension of quality.

Taking this argument even further, we can expand the quality ranking measures to use both $\mathrm{q}_{21}$ and $\mathrm{q}_{22}$, as shown in Column (4) of Table $5 .{ }^{21}$ As in Column (3), only the scholar's ranking in total citations has a significant effect on the reputation of the school that hired him/her. There is no evidence of a significant additional impact of either the most- or second-most-cited paper. What matters for reputation is the overall quality of the works that an author has produced. ${ }^{22}$

\footnotetext{
${ }^{20}$ When we add an indicator for public institutions (53 of the 88 schools in the sample), there are no qualitative changes in the results in the table, although, other things equal, public institutions are ranked lower.

${ }^{21}$ The simple correlation between the numerical proxies for these quality measures is 0.83 .

${ }^{22}$ The partial correlation coefficient between $\mathrm{q}_{1}$ and the vector $\mathrm{q}_{21}$ through $\mathrm{q}_{25}$ is 0.972 , making it difficult to move beyond the estimates presented in Column (4).
} 
Relying on the formulation in Column (3), we can examine how reputation is affected by quantity and quality at different levels of the ranking of quality. In other words, do their effects on reputation differ at the margin depending on the scholar's ability to generate reputation at different levels? To examine this we estimate quantile regressions at the $75^{\text {th }}$ percentile, the median and the $25^{\text {th }}$ percentile of the quality rankings of departments. The results of the estimation are shown in Columns (5)-(7). The differences on the crucial variables are not great - at all three quartile boundaries $\mathrm{q}_{1}$ has the same positive significant effect that it has at the means, $\mathrm{q}_{21}$ has the same insignificant effect, and $\mathrm{Q}$ has the same negative effect. Perhaps most interesting are the smaller effects of $\mathrm{Q}$ and $\mathrm{q}_{1}$ at the upper quartile, although these differences are at least partly due to the greater number of full professors at the higher-ranked schools, so that by construction a change in an independent variable cannot generate as big a change in ranking.

In Section II we argued that our estimates are tracing out the hedonic locus between scholarly output - quantity and various dimensions of quality — and scholarly reputation. To what extent can we interpret the estimates as reflecting the preferences of buyers of quantity and quality in this reputational market? This depends on the extent to which scholars (suppliers of reputation) can substitute along the different margins of quality, and between quantity and quality. If each produces along a Leontief-type function, then the estimates that we have presented of the market locus reflect only the values that buyers attach to the determinants of reputation, given the fixed supply along each margin. If suppliers are able to substitute along these margins, then the failure of the market returns to be equated at all margins (the facts that overall quality generates extra rewards and that quantity per se has no or even a negative impact) suggests either that suppliers are unaware of the differential returns or that they cannot fully substitute at all margins. Either way, the possible existence of some substitution by suppliers of reputation along these margins implies that, if anything, our results understate the degree of inequality of the partial derivatives in the demand functions $\mathrm{R}^{\mathrm{D}}{ }_{\text {. }}$.

\section{Reputation Reflected in Mobility}

An additional way of examining the roles of quantity and quality in generating reputation using schools' reputational ratings is to study the quality of the department into which new full professors were 
hired between 1992 and 2007. We assume here that the decision to hire a new full professor in this period reflects decision-makers' beliefs that the person will add to the reputation of the department (his/her reputation is at least that of the collective's average without him/her). Accordingly, a lower-bound measure of the individual's reputation is the reputation of the department some time shortly before s/he joined it.

For the scholars in our sample who moved between schools from 1992 to 2007 or who entered the job market after 1992, we relate the 1993 NRC quality rating to the variables included in the equations presented in Table 5, using both least-squares estimates at the means of the relationship and quantile estimates at the quartiles. The scholarship of the 325 sample respondents who were hired by the schools in our sample after 1992 and were full professors in 2007-08 could not have affected the quality rating of the school in 1993. Thus relating the 1993 NRC rating to the individuals' efforts is an even cleaner measure of the impact of the quantity and quality inputs on reputation than that used in the previous subsection, under the maintained assumption that schools will not hire or tenure scholars who reduce their reputations.

The estimates are shown in Table 6. As in all the estimates in which we use departmental reputation as a proxy for the lower bound on the scholar's reputation, there is no relationship between reputation and the measure of quantity that we use to proxy Q. Indeed, remembering that a higher rank means fewer papers, we see from the results in Column (3) that there is a significant negative impact of Q on reputation. As with all the other measures that we have examined in this Section, merely writing more papers, conditional on the overall quality of one's work, may even reduce one's reputation. As the results in Columns (1)-(3) show, only $\mathrm{q}_{1}$ significantly increases what we have identified as the lower bound of the scholar's reputation (remembering that the outcome, NRC rating, is increasing in quality, while the numerical ranking of a scholar's quality is decreasing in quality). Moreover, as in nearly all our other efforts to describe various proxies for reputation, the marginal effect of additional quality is diminishing; and, as before, it is quality ranking rather than absolute quality that describes the outcome better. In this sub-sample, moreover, increasing $\mathrm{q}_{21}$ has essentially no effect on reputation-only the total number of citations matters. 
The effects of quantity and the dimensions of quality on the scholar's reputation (as proxied by the reputation of the department that hired him/her) are not greatly different at various quartiles of the reputational distribution, but some small differences are noticeable. The beneficial effects of $\mathrm{q}_{1}$ on reputation do not change significantly as we move down the quality distribution; and while the negative conditional effect of additional output on reputation is larger at the top quartile, the impacts are not significantly different across quartiles. Also, as with the least-squares estimates, $\mathrm{q}_{21}$ has no significant effect on reputation at any of the quartiles.

As with the estimates for the entire sample, we can interpret the results on movers in the context of the hedonic model. So long as the parameters of (1) and (2) are unchanging, or changing very slowly over time, we can again infer that the importance of $\mathrm{q}_{1}$ and the unimportance or negative impact of $\mathrm{Q}$ on reputation suggest either that suppliers cannot or do not substitute along these dimensions or that the demand-side effects are even larger than our estimates suggest.

\section{The Non-Reputational Returns to Quality and Quantity}

\section{A. The Impact on Mobility}

Assuming as we have that universities seek to maximize their reputations through the reputations of their faculty, one would expect that we would observe the same effects of our measures of quality and quantity on the payoffs that universities offer to attract and/or retain faculty. Thus we initially examine the impact of these measures on the likelihood that an individual whose first publication appeared before 1987 was hired with tenure between 1992 and 2007. Of the full professors in the sample 924 presumably could have moved with tenure to the department in which they are now located. Of those eligible by this criterion for inclusion in the sub-sample, in 200721 percent were at departments different from the one that employed them in 1992.

In Table 7 we report the results of estimating probits describing whether one of the members of this sub-sample moved during this fifteen-year period, as determined by the number of publications and several dimensions of their quality. Not surprisingly, having published one's first paper more recently has a strong significant positive effect on the probability that one changed jobs. This is consistent with declining voluntary and involuntary mobility with age. In one crucial way, however, the results differ 
completely from all of those describing the relation of quantity and quality to reputation in the previous Section: Whereas the quantity of publications had no or even a negative impact on the receipt of awards or one's reputation as proxied by the reputation of one's employer, the probability of moving is strongly positively related to the number of publications one has generated. This result may merely reflect the fact that movers are a doubly selected sample: While they have to meet at least the reputational median of the department that hires them, other scholars may have at least as high a reputation but reject mobility, either because they reject formal job offers or because it is known that they do not seek them. Another possibility is that competing departments may view a higher Q among younger (more mobile) scholars as a signal of their likely subsequent development of quality. Yet another explanation for this result is that it is easier for universities to obtain information on the quantity of output than on its quality - that university administrators are unable to process information on quality as easily as they can data on quantity when they consider hiring new faculty.

\section{B. The Impact on Salary}

To examine more closely this apparent disconnect between the determinants of individuals' reputations and the determinants of individuals' non-reputational returns, we examine the salary data that we collected for 2007-08 for 571 full professors in 43 public universities. Although we only have salary data on 42 percent of the economists comprising our sample, this group of faculty members at public universities should be sufficiently large to allow us to explore a comparison of the impacts of Q, $\mathrm{q}_{1}$ and $\mathrm{q}_{21}$ on salary to their impacts on reputation.

We stress that the observations that we use in this sub-section are not a random sub-sample: Unsurprisingly, since private universities are typically higher-ranked (e.g., the leading public-university department in our sample is ranked ninth in the world, behind those of eight private U.S. institutions), the members of the sub-sample have fewer citations in total (median of 250 compared to 309 in Table 2), fewer citations to their most-cited paper (median of 57 compared to 71), but nearly the same number of papers (median of 22 compared to 24 ). ${ }^{23}$ Moreover, we could not obtain salary information on 10 of the

\footnotetext{
${ }^{23}$ Indeed, the distributions of citations and numbers of publications are similar below the median, but the overall distributions have longer right tails.
} 
53 public institutions in the sample, and those individuals on whom we have usable salary and citations data have slightly, but statistically insignificantly lower averages of $\mathrm{Q}, \mathrm{q}_{1}$ and $\mathrm{q}_{2 \mathrm{n}}$ than those publicuniversity faculty members on whom we do not have salary information.

Regressions of the logarithms of nine-month salaries against the same combinations of citations and publications measures used in the previous sections are shown in Columns (1)-(3) of Table 8. The usual control variables are included too, along with school fixed effects. ${ }^{24}$ As with the reputational measures, salaries are described better by ranks in citations in total and to top-cited papers than by raw numbers. Thus in the discussion we concentrate on the results in Column (3). As before, total citations have a significant positive effect on salary (remembering that a lower-numbered rank implies more total citations). The effect is not small: Going from the $25^{\text {th }}$ to the $75^{\text {th }}$ percentile of total citations in this subsample raises salary by 29 percent, and from the $5^{\text {th }}$ to the $95^{\text {th }}$ by 63 percent (on a mean of $\$ 149,900$ ).

Unlike its impact on reputation, which for some of the proxies was positive, here as in the results in the previous sub-section there is no significant additional effect of citations to the author's most-cited paper-indeed, it seems to have less of an effect on salary than citations to the scholar's other work. Moreover, unlike the results on direct measures of reputation, but like that on the probability of moving, and as shown in some studies of academic salaries, Q has a positive and statistically significant effect on salary. The effect is moderate: Using the results in Column (1), going from the $25^{\text {th }}$ to the $75^{\text {th }}$ ( $5^{\text {th }}$ to the $95^{\text {th }}$ ) percentile of Q increases salary by 5 (9) percent), but it stands in sharp contrast to the results on reputation itself in this study.

One might be concerned that the results on salary arise simply because the sub-sample differs along quality dimensions from the overall sample. To examine this possibility, in Columns (4) and (5) of Table 8 we re-estimate the equations in Columns (6) of Table 4 and (3) of Table 5, here using the subsample of public university faculty on whom we have salary data. ${ }^{25}$ The impacts of Q and $\mathrm{q}_{1}$ on Fellow are smaller in absolute value in this sub-sample, but they are qualitatively not that different from those for

\footnotetext{
${ }^{24}$ While the vector of fixed effects is highly significant statistically, its inclusion changes none of the inferences about the impacts of the citations and publication measures on salary. The results are also qualitatively nearly identical if we replace the school fixed effects with the department's ranking as used in the previous sections; and the correlation of ranking with average salary is -0.73 .

${ }^{25}$ We do not use Honored here, as only 5 of the 571 observations received an honor, while 63 are Fellows.
} 
the entire sample. The estimated impacts of the quality and quantity measures on departmental ranking are nearly identical in this sub-sample to those in the entire sample. Overall the results in Table 8 suggest that the effect of Q on proxies for an individual's reputation is at the very least quite different from its effect on his/her salary. ${ }^{26}$

The contrast between the effects of Q in Column (3) of Table 8, and in Columns (4) and (5), poses an interesting conundrum: Why should universities pay off on something - the sheer volume of production - that, as our results demonstrate, does not raise and may even reduce an individual's reputation? One possibility is that those who determine salaries are unaware of citation information or do not take it into account, so that Q provides the only signal of productivity (remember that $\mathrm{Q}$ and the $\mathrm{q}$ measures are positively correlated). As one effort to examine this possibility, we surveyed individuals in the departments used in this sub-section, obtaining data on whether information on recent accepted/published work, and/or recent citations, is collected for use in determining annual salary changes. ${ }^{27}$ We obtained responses from all 43 departments, with the unsurprising result that all obtain information on publications; but only 8 departments, covering 120 of the 571 individuals included in the estimates in Table 8, obtain information on annual citations. The contrast between the results on salary and reputation may therefore simply arise from most schools ignoring citation information in salarysetting.

If these results stem from the failure of most institutions to obtain information on citations, we would expect to see that the number of publications affects salary determination less in those departments that do collect citations data, while total citations and citations to the most-cited paper have greater effects there. Adding interactions of an indicator for collecting citations data with $\mathrm{Q}, \mathrm{q}_{1}$ and $\mathrm{q}_{21}$ to Column (3) of Table 8 , we find that none of the interactions has a t-statistic above one, and the vector of interactions is not statistically significant $(F(3,518)=0.11)$. Entering each interaction term separately does not alter the

\footnotetext{
${ }^{26}$ Replicating the results in Table 7 for the eligible members of this sub-sample, we find only minor changes in the estimates although, with the much-reduced sample size, the significance of the estimates is reduced.

${ }^{27}$ The e-mail questionnaire was: "In doing annual merit/salary reviews, what information is requested from faculty members in your Department? 1) List of articles accepted and/or published during the year-YES or NO. 2) List or count of citations during the year to published or unpublished work-YES or NO. Please delete the incorrect answer to each of these two questions."
} 
conclusion. While some schools do collect citation data when salaries are determined, having that information available does not seem to alter the determinants of salaries. Unlike our measures of reputation, wages are based on academic productivity per se; and quantity may to some extent proxy nonreputational inputs such as teaching skills, public-service orientation and administrative/organizational skills. $^{28}$

Another explanation may be that the salaries of those who have moved into a department are determined differently from those of stayers (although the evidence in the previous sub-section suggested the same effects on the probability of moving that we have observed here on salaries). Taking the 404 members of the sub-sample whose first publication was before 1987, we re-estimate the salary equation including an indicator for having moved between 1992 and 2007 and its interactions with Q, $\mathrm{q}_{1}$ and $\mathrm{q}_{21}$. While all three interactions have signs opposite the main effects, the F-statistic jointly testing their equality to zero is $F(3,350)=1.02$, not statistically significant; and none of the interactions individually had a t-statistic above one in absolute value. ${ }^{29}$

All in all, we are left with no satisfactory explanation for the disconnect between the determinants of direct measures of reputation and the determinants of salary. One (untestable) possibility is that the same personality characteristics that lead scholars to churn out many papers also lead them to agitate more successfully for salary increases, either by soliciting and receiving job offers and/or by clever negotiation with their current employer. Regardless, taken together the results suggest that salaries are affected by total citations but not by their concentration on a scholar's most-cited work. Overall, this subsection provides no evidence of any impact of $\mathrm{q}_{21}$ on salary, perhaps different from its effect on reputational measures. Salary is also affected by the sheer quantity of what is published, in contrast to its

\footnotetext{
${ }^{28}$ One might also guess that higher-ranked schools pay more attention to total citations, which as we showed are the major determinant of reputation, and less to Q. Re-estimating the equation in Column (3) of Table 8 by adding the interactions of the department's ranking with $\mathrm{Q}, \mathrm{q}_{1}$ and $\mathrm{q}_{21}$ generated quite insignificant parameter estimates on the interactions individually and as a group $(\mathrm{F}(3,518)=0.70$. $)$

${ }^{29}$ The main effect of the indicator for moved was highly significant and implied that, other things equal, those who had moved earned 18 percent more per year than otherwise identical faculty who had not. This result is consistent with the Ransom's (1993) findings on the relation between academic salaries and job tenure.
} 
absence or even negative effect on reputation in the entire sample and in this sub-sample of public institutions. $^{30}$

\section{Conclusions}

We have used the careers of academic economists as a simulacrum for studying the determinants of reputation. Reputation is a very nebulous concept, and for that reason we have been compelled to find a number of proxies for it, none of which, we admit, could possibly capture the idea fully. Our focus has been on the relative roles of what might be characterized as the number of attempts to establish reputation, the number of actual impressions made on those who might determine one's reputation and the distribution of those impressions across their number. We proxy the number of attempts by the number of papers a scholar has published, their impressions by the number of times those published works are cited, and their distribution by the concentration of citations on one or several published papers.

Although the evidence is somewhat mixed, it appears that, at least in this example, simply attempting to establish a reputation by writing more papers has essentially no impact on subjective measures of reputation and perhaps even a negative effect. It does, however, affect the likelihood that a scholar is able to change jobs, and it also raises salaries in the sub-sample we have used. The major determinant of reputation - what is rewarded in this particular academic reputational market - is the interest that a scholar's work generates among his/her peers. There is at most only weak evidence that the concentration of impressions on a single piece of work - one article, in this case - generates additional increases in one's reputation. Finally, we also find evidence that this reputational market has tournamentlike aspects - one's ranking along the dimension of overall quality appears to describe one's reputation better than do one's absolute achievements along this dimension.

With the disconnect between the determinants of reputation and the determinants of salary, assuming that the goals of universities are best achieved by enhancing their reputation rather than by paying for characteristics that do not enhance reputation, there is an opportunity for a smart university

\footnotetext{
${ }^{30}$ Nor are salaries lower, other things equal, as a compensating differential for those who have better reputations: For Fellow $=1$ in re-estimates of Column (3) of Table 8 salaries are a significant 10 percent higher, other things equal; but the qualitative impacts of $\mathrm{Q}, \mathrm{q}_{1}$ and $\mathrm{q}_{21}$ are unchanged. No doubt employer-provided honorifics are traded off for pecuniary returns in compensation packages (see Besley and Ghatak, 2008). The result here implies either that universities provide extra monetary rewards for professors who obtain external recognition and/or that having obtained that recognition provides information in salary-setting that is not provided by our other measures.
} 
administrator to reallocate resources in salary-setting and improve his/her institution's position. Paying off at the margin more on reputation and less on quantity would be a sensible approach. One would think that, with the recognition of this disconnect, we would see markets working to remove these differences at the margin. $^{31}$

While our example is obviously quite specific, the general view of a market in which various characteristics are implicitly supplied and purchased and interact to generate reputation seems useful in a variety of other reputational market contexts. Any labor market in which the participants' output can be identified would appear equally amenable to studying the quantity/quality determinants of reputation. The establishment of reputation in other academic disciplines and in the professions can mutatis mutandis be analyzed using essentially the same methods that we have used here; and the nature of reputation in artistic/creative activities is similar enough to that in academic disciplines to make studying it using approaches like the one here worth pursuing. Going beyond labor markets, the reputations of journals themselves could be studied using their various dimensions of quality and quantity. Also, the reputations of restaurants, and perhaps other retail outlets, might be studied in the same way. The main points are that it is useful to view the establishment of reputation as stemming from market interactions and that the various determinants of reputation can be analyzed in a wide variety of real-world contexts.

\footnotetext{
${ }^{31}$ If general managers of major league baseball teams can recognize these profit opportunities, as they seem to have (see Hakes and Sauer, 2006), one would think that highly intelligent department and university administrators would also be able to do so.
} 


\section{REFERENCES}

Michelle M. Arnold and D. Stephen Lindsay. 2002. "Remembering Remembering," Journal of Experimental Psychology: Learning, Memory and Cognition, 28(3), 512-529.

Kaushik Basu. 1989. “A Theory of Association: Social Status, Prices and Markets," Oxford Economic Papers, 41(4), 653-671.

Timothy Besley and Maitreesh Ghatak. 2008. "Status Incentives," American Economic Association, Papers and Proceedings, 98(2), 206-211.

George Borjas. 1987. "Self-Selection and the Earnings of Immigrants," American Economic Review, 77(4), 531-553.

Bernt Bratsberg, James Ragan and John Warren. 2009. "Does Raiding Explain the Negative Returns to Faculty Seniority?” Economic Inquiry, forthcoming.

Ana Cardoso, Paulo Guimaraes and Klaus Zimmermann. 2008. "Comparing the Early Research Performance of Ph.D. Graduates in Labor Economics in Europe and the USA," Unpublished Paper, IZA Bonn, May.

Jonathan Cole and Stephen Cole. 1973. Social Stratification in Science. Chicago: University of Chicago Press.

CSWEP. 2007. "Report of the Committee on the Status of Women in the Economics Profession," American Economic Association, Papers and Proceedings, 97(2), 566-572.

Liran Einav and Leeat Yariv. 2006. "What's in a Surname? The Effects of Surname Initials on Academic Success," Journal of Economic Perspectives, 20(1), 175-188.

David J. Faurot and Stephen McAllister. 1992. "Salary Arbitration and Pre-Arbitration Negotiation in Major League Baseball," Industrial and Labor Relations Review, 45(4), 697-710.

Marianne A. Ferber. 1986. “Citations: Are They an Objective Measure of Scholarly Merit?" Signs, 11(2): 381-389.

John Hakes and Raymond Sauer. 2006. “An Economic Evaluation of the Moneyball Hypothesis," Journal of Economic Perspectives, 20(3), 173-186.

Daniel S. Hamermesh, George E. Johnson and Burton A. Weisbrod. 1982. "Scholarship, Citations and Salaries: Economic Rewards in Economics,” Southern Economic Journal, 49(2), 472-481.

Daniel S. Hamermesh and Peter Schmidt. 2003. "The Determinants of Econometric Society Fellows Elections," Econometrica, 71(1), 399-407.

Jorge E. Hirsch. 2005. “An Index to Quantify an Individual's Scientific Research Output," Proceedings of the National Academy of Sciences, 102(46), 16569-16572.

Pantelis Kalaitzidakis, Theofanis P. Mamuneas and Thanasis Stengos. 2003. "Rankings of Academic Journals and Institutions in Economics," Journal of the European Economic Association, 1(4), 1346-1366.

Lawrence M. Kahn. 1993. "Free Agency, Long-Term Contracts and Compensation in Major League Baseball: Estimates from Panel Data," Review of Economics and Statistics, 73(1), 157-164. 
Kenneth Kurtz and Jeffrey Loewenstein. 2007. "Converging on a New Role for Analogy in Problem Solving and Retrieval: When Two Problems Are Better Than One," Memory and Cognition, 35(2), 334-341.

Edward P. Lazear and Sherwin Rosen. 1981. "Rank-Order Tournaments as Optimum Labor Contracts," Journal of Political Economy, 89(5), 841-864.

George Mailath and Larry Samuelson. 2006. Repeated Games and Reputation: Long-Run Relationships. New York: Oxford University Press.

William J. Moore, Robert J. Newman and Geoffrey K. Turnbull. 1998. "Do Academic Salaries Decline with Seniority?" Journal of Labor Economics, 16(2), 352-366.

National Research Council. 1995. Research-Doctorate Programs in the United States; Continuity and Change. Washington: National Academy of Sciences.

Michael Ransom. 1993. "Seniority and Monopsony in the Academic Labor Market," American Economic Review, 83(1), 221-233.

Sherwin Rosen. 1974. "Hedonic Prices and Implicit Markets," Journal of Political Economy, 82(1), 3455.

1987. “Some Economics of Teaching,” Journal of Labor Economics, 5(4), 561-575.

Yianis Sarafidis. 2007. "What Have You Done for Me Lately? Release of Information and Strategic Manipulation of Memories," Economic Journal, 117(2), 307-326.

Aloysius Siow. 1991, “Are First Impressions Important in Academia?" Journal of Human Resources, 26(2), 236-255.

Jeffrey J. Starns and Jason L. Hicks. 2005. "Source Dimensions Are Retrieved Independently in Multidimensional Monitoring Tasks," Journal of Experimental Psychology: Learning, Memory and Cognition, 31(6), 1213-1220.

Jean Tirole. 1996. "A Theory of Collective Reputations (with application to the persistence of corruption and to firm quality)," Review of Economic Studies, 63(1), 1-22.

Endel Tulving and Donald M. Thomson. 1973. "Encoding Specificity and Retrieval Processes in Episodic Memory," Psychological Review, 80(5), 352-373.

Benjamin Ward. 1958. "The Firm in Illyria: Market Syndicalism," American Economic Review, 48(4), 566-589. 
Table 1. Means and Standard Deviations, Outcome Measures, Full Professors in Top-Rated Departments, 2007-08, N=1350

\section{Outcome}

Reputational Ranking (1 top, 200 bottom)* $\quad 62.91$

NRC93Quality Rating (5 highest)

3.25

Moved 93-07

0.201

( $\mathrm{N}=924$ eligibles)

0.032

Honored (w/o Clark)

0.026

Fellow

0.204

*From Kalaitzidakis et al (2003). 
Table 2. Descriptive Statistics, Personal Measures, Full

Professors in Top-Rated Departments, 2007-08, N=1350

\begin{tabular}{|c|c|c|c|c|c|c|c|c|}
\hline \multicolumn{9}{|c|}{ Percentile } \\
\hline Citations: & Mean & Minimum & 5 & 25 & 50 & 75 & 95 & Maximum \\
\hline $\mathrm{q}_{1}$ & 687 & 0 & 26 & 131 & 309 & 727 & 2578 & 14232 \\
\hline $\begin{array}{l}\mathrm{q}_{2 \mathrm{n}}: \\
1 \text { st Paper }\end{array}$ & 150 & 0 & 9 & 32 & 71 & 156 & 501 & 4580 \\
\hline 2nd Paper & 83 & 0 & 5 & 21 & 44 & 91 & 261 & 2212 \\
\hline 3rd Paper & 59 & 0 & 3 & 15 & 32 & 68 & 189 & 1059 \\
\hline 4th Paper & 47 & 0 & 2 & 11 & 25 & 53 & 153 & 879 \\
\hline 5th Paper & 38 & 0 & 1 & 8 & 20 & 43 & 127 & 717 \\
\hline Q & 31.95 & 1 & 7 & 14 & 24 & 39 & 83 & 283 \\
\hline Female & 0.060 & & & & & & & \\
\hline $\begin{array}{l}\text { English- } \\
\text { language } \\
\text { education }\end{array}$ & 0.779 & & & & & & & \\
\hline $\begin{array}{l}\text { No. of Full } \\
\text { Professors }\end{array}$ & 19.45 & 3 & 7 & 12 & 17 & 24 & 35 & 39 \\
\hline
\end{tabular}


Table 3. Top 20 Authors by Citations, Citations to Most-Cited Paper, and Total Papers

$\begin{array}{llllll}\text { AUTHOR } & \begin{array}{l}\text { Total } \\ \text { Cites }\end{array} & \text { AUTHOR } & \begin{array}{l}\text { Most- } \\ \text { Cited } \\ \text { Paper }\end{array} & \text { AUTHOR } & \text { Total Papers } \\ \text { Stiglitz, Joseph E. } & 14232 & \text { White, Halbert L. } & 4580 & \text { Cooper, Richard N. } & 283 \\ \text { Engle, Robert F. } & 12301 & \text { Engle, Robert F. } & 3592 & \text { Phillips, Peter C.B. } & 279 \\ \text { Shleifer, Andrei } & 11038 & \text { Granger, Clive W.J. } & 3592 & \text { Smith, V. Kerry } & 241 \\ \text { Becker, Gary S. } & 11010 & \text { Heckman, James J. } & 3201 & \text { Stiglitz, Joseph E. } & 232 \\ \text { Phillips, Peter C.B. } & 10805 & \text { Hausman, Jerry A. } & 2073 & \text { Engerman, Stanley } & 197 \\ \text { Heckman, James J. } & 10522 & \text { Newey, Whitney K. } & 1781 & \text { Lave, Lester B. } & 185 \\ \text { Barro, Robert J. } & 9941 & \text { West, Kenneth D. } & 1781 & \text { Turnovsky, Stephen J. } & 179 \\ \text { Lucas, Robert E. } & 9630 & \text { Akerlof, George A. } & 1746 & \text { Brada, Josef C. } & 172 \\ \text { Granger, Clive W.J. } & 8966 & \text { Hansen, Lars Peter } & 1738 & \text { DeGregori, Thomas R. } & 171 \\ \text { White, Halbert L. } & 7834 & \text { Lucas, Robert E. } & 1681 & \text { Bhagwati, Jagdish N. } & 168 \\ \text { Ross, Stephen } & 7082 & \text { Becker, Gary S. } & 1570 & \text { Feldstein, Martin } & 168 \\ \text { Milgrom, Paul R. } & 6945 & \text { Bollerslev, Tim } & 1568 & \text { Jorgenson, Dale } & 165 \\ \text { Hausman, Jerry A. } & 6790 & \text { Phillips, Peter C.B. } & 1364 & \text { Behrman, Jere R. } & 164 \\ \text { Williamson, Oliver E. } & 5963 & \text { Perron, Pierre } & 1364 & \text { Shogren, Jason F. } & 163 \\ \text { Hansen, Lars Peter } & 5279 & \text { Sims, Christopher A. } & 1334 & \text { Fare, Rolf } & 162 \\ \text { Feldstein, Martin } & 5252 & \text { Nelson, Charles R. } & 1197 & \text { Sloan, Frank A. } & 160 \\ \text { Prescott, Edward C. } & 5166 & \text { Barro, Robert J. } & 1154 & \text { Williamson, Jeffery G. } & 157 \\ \text { Hart, Oliver } & 5115 & \text { Stiglitz, Joseph E. } & 1147 & \text { Baer, Werner } & 155 \\ \text { Bollerslev, Tim } & 5021 & \text { Dixit, Avinash K. } & 1094 & \text { Granger, Clive W.J. } & 154 \\ \text { Stock, James H. } & 4973 & \text { Holmstrom, Bengt R. } & 1063 & \text { Viscusi, W. Kip } & 137\end{array}$


Table 4. Effects of Total Citations and Most-Cited Paper on

Honors, Probit Derivatives, N=1350*

(1)

Ind. Var.:

Total Citations/1000
(3)

Honored
(4)

(5)

Fellow

(6)

\begin{tabular}{|c|c|c|c|c|c|c|}
\hline Total Citations/1000 & $\begin{array}{c}0.0050 \\
(3.42)\end{array}$ & $\begin{array}{c}0.0064 \\
(3.16)\end{array}$ & & $\begin{array}{l}0.250 \\
(7.91)\end{array}$ & $\begin{array}{l}0.335 \\
(9.07)\end{array}$ & \\
\hline $\begin{array}{l}\text { (Total } \\
\text { Citations } / 1000)^{2}\end{array}$ & & $\begin{array}{c}-0.00038 \\
(2.89)\end{array}$ & & & $\begin{array}{c}-0.0202 \\
(8.24)\end{array}$ & \\
\hline $\begin{array}{l}\text { Citations to Most- } \\
\text { Cited Paper/1000 }\end{array}$ & $\begin{array}{l}0.0055 \\
(1.05)\end{array}$ & $\begin{array}{c}0.0092 \\
(1.18)\end{array}$ & & $\begin{array}{l}0.201 \\
(1.63)\end{array}$ & $\begin{array}{l}0.112 \\
(0.88)\end{array}$ & \\
\hline $\begin{array}{l}\text { (Citations to Most- } \\
\text { Cited Paper/1000) }\end{array}$ & & $\begin{array}{c}-0.0019 \\
(1.10)\end{array}$ & & & $\begin{array}{c}-0.0473 \\
(1.36)\end{array}$ & \\
\hline No. of Entries/1000 & $\begin{array}{l}0.025 \\
(0.55)\end{array}$ & $\begin{array}{l}0.015 \\
(0.47)\end{array}$ & & $\begin{array}{r}-1.383 \\
(2.14)\end{array}$ & $\begin{array}{l}-1.808 \\
(2.91)\end{array}$ & \\
\hline $\begin{array}{l}\text { Total Citations } \\
\text { Rank/1000 }\end{array}$ & & & $\begin{array}{l}-0.0035 \\
(1.93)\end{array}$ & & & $\begin{array}{c}-0.565 \\
(7.39)\end{array}$ \\
\hline $\begin{array}{l}\text { Citations to Most- } \\
\text { Cited Paper } \\
\text { Rank/1000 }\end{array}$ & & & $\begin{array}{l}-0.0014 \\
(1.06)\end{array}$ & & & $\begin{array}{c}0.0140 \\
(0.24)\end{array}$ \\
\hline $\begin{array}{l}\text { No. of Entries Rank } \\
/ 1000\end{array}$ & & & $\begin{array}{l}-0.00051 \\
(0.61)\end{array}$ & & & $\begin{array}{l}0.120 \\
(3.13)\end{array}$ \\
\hline English Education & $\begin{array}{c}-0.00066 \\
(0.14)\end{array}$ & $\begin{array}{c}0.00013 \\
(0.04)\end{array}$ & $\begin{array}{l}0.00013 \\
(0.33)\end{array}$ & $\begin{array}{r}-0.199 \\
(6.12)\end{array}$ & $\begin{array}{c}-0.199 \\
(6.39)\end{array}$ & $\begin{array}{r}-0.173 \\
(6.72)\end{array}$ \\
\hline Pseudo- $\mathrm{R}^{2}$ & 0.401 & 0.443 & 0.431 & 0.312 & 0.337 & 0.356 \\
\hline
\end{tabular}

\footnotetext{
*Absolute values of t-statistics in parentheses here and in Tables 5-8. Also included in all the probits for Honored are place in the alphabet and year of first paper. The probits for fellow elections add an indicator for female.
} 
Table 5. Effects of Total Citations and Most-Cited Paper(s)

On Departmental Rankings, $\mathrm{N}=1197 *$

Ind. Var.:

Total Citations/100

$(\text { Total Citations } / 100)^{2}$

Citations to Most-

Cited Paper/100

(Citations to Most-

Cited Paper $/ 100)^{2}$

No. of Entries/100

Total Citations Rank

Citations to Most-

Cited Paper Rank

Citations to Second-

Most Cited Paper

Rank

No. of Entries Rank

$/ 1000$

Year of 1st Paper

English Education

No. of Full Professors

$\mathrm{R}^{2}$
(1)

(2)

$-0.458 \quad-1.328$

(1.68) (2.38)

.0103

(2.69)

$-1.200 \quad-2.674$

(1.41) (2.40)

0.0583

(2.49)

$0.849 \quad 4.237$

$(0.14) \quad(0.62)$
(3)

(4)

Top

quartile

(5)

(6)

Bottom

quartile

(7) )
Quantile

Regressions

Median 
Table 6. Effects of Total Citations and Most-Cited

Paper on 1993 Departmental Rating, N = 315 Movers

OLS

Ind. Var.:

(1)

(2)

(3)

$\begin{array}{lcc}\text { Total Citations/1000 } & \begin{array}{c}0.188 \\ (1.75)\end{array} & \begin{array}{c}0.542 \\ (3.90)\end{array} \\ & & \\ & & -0.0244 \\ {\text { (Total Citations } / 100)^{2}} & & (3.59) \\ & & \\ \text { Citations to Most- } & -0.0180 & 0.0827 \\ \text { Cited Paper/1000 } & (0.04) & (0.12) \\ & & -0.709 \\ \text { (Citations to Most- } & & (1.64) \\ \text { Cited Paper/100) } & \\ & & \\ \text { No. of Entries/100 } & -0.0015 & -0.381 \\ & (0.59) & (1.48)\end{array}$

Total Citations Rank

$\begin{array}{cccc}-0.00144 & -0.00168 & -0.00080 & -0.00102 \\ (3.28) & (2.75) & (1.54) & (1.97)\end{array}$

Citations to Most-

Cited Paper Rank

No. of Entries Rank

$\begin{array}{cccc}0.00034 & 0.00029 & -0.00001 & 0.00026 \\ (1.08) & (0.61) & (0.03) & (0.60)\end{array}$

$\begin{array}{llll}0.00065 & 0.00091 & 0.00039 & 0.00036\end{array}$

$(2.61) \quad(2.61) \quad(1.30)$

Year of 1st Paper

$$
0.0314 \quad 0.0379
$$

0.0337

0.0348

0.0269

0.0277

(3.63)

(4.27)

(4.19)

(3.19)

(3.07)

English Education

$$
0.191 \quad 0.160
$$

0.123

0.117

0.134

0.153

(2.29)

(1.71)

(0.87)

(1.12)

(1.26)

No. of Full Professors

0.0740

0.0699

0.0700

0.0523

0.0742

0.0837
(8.43)
(8.21)

(7.80)

(6.77)

(10.57)

(12.58)

$\mathrm{R}^{2}$

0.495

0.521

0.528

0.316

0.368

0.330

*t-statistics based on robust standard errors in Columns (1)-(3). 
Table 7. Effects of Total Citations and Most-Cited Paper on

Moving Between 1992 and 2007, Probit Derivatives, N=924
(1)
(2)
(3)

Ind. Var.:

Total Citations $/ 1000$

$\begin{array}{ll}0.0582 & 0.129 \\ (2.94) & (3.69)\end{array}$

$(\text { Total Citations/1000) })^{2}$

$-0.0084$

Citations to Most-

$-0.170 \quad 0.0172$

Cited Paper/1000

(Citations to Most-

$-0.175$

Cited Paper/1000) ${ }^{2}$

No. of Entries/100

$\begin{array}{cc}0.2066 & 0.168 \\ (4.39) & (3.25)\end{array}$

Total Citations

Rank

$-0.00040$

(3.63)

Citations to Most-

Cited Paper Rank

0.00017

(1.94)

No. of Entries Rank

$-0.00011$

(1.87)

Year of 1st Paper

$0.0154 \quad 0.0153$

0.0149

(7.31)

(7.40)

(7.33)

English Education

$-0.109$

$-0.102$

$-0.099$

(2.80)

(2.72)

(2.63)

Pseudo-R ${ }^{2}$

0.108

0.137

0.154 
Table 8. Effects of Total Citations and Most-Cited Paper(s)

on Salary, Departmental Ranking and ES Fellow, $N=571$

(43Departments)

\section{Dependent Variable:}

Ind. Var.:

Total Citations $/ 100$

$(\text { Total Citations } / 100)^{2}$

Citations to Most-

Cited Paper/100

(Citations to Most-

Cited Paper $/ 100)^{2}$

No. of Entries/100

Total Citations Rank/1000

Citations to Most-

Cited Paper Rank/1000

No. of Entries Rank/1000

English Education

p-value on F-test of 42 School

Fixed Effects

Adj. $\mathrm{R}^{2}$ (Pseudo- $\mathrm{R}^{2}$ in Col. (5))
Ln(Salary)

(2)

(3)

Fellow

(4)

(1)

$0.0221 \quad 0.0388$

(6.87)

(6.98)

$-0.00057$

(4.58)

$\begin{array}{ll}-0.0284 & -0.0297\end{array}$

(3.95)

(2.25)

0.00105

(2.75)

$\begin{array}{ll}0.166 & 0.121 \\ (3.30) & (2.32)\end{array}$$$
(2.32)
$$

Ranking

(5) $\begin{array}{lll}-0.421 & -0.229 & 59.81\end{array}$

$\begin{array}{lll}(5.59) & (3.48) \quad(3.42)\end{array}$

$\begin{array}{lll}0.118 & -0.0312 & -0.363\end{array}$

$\begin{array}{lll}(1.95) & (0.62) & (0.03)\end{array}$

$\begin{array}{lll}-0.077 & 0.0528 & -30.74\end{array}$

$\begin{array}{lll}(2.06) & (1.55) \quad(2.47)\end{array}$

$\begin{array}{lllll}-0.0201 & -0.0238 & -0.0200 & -0.0468 & 10.280\end{array}$

$\begin{array}{llll}(0.84) & (1.01) & (0.87) & (1.99)\end{array}$

$<.001<.001<.001$

$\begin{array}{lllll}0.490 & 0.511 & 0.528 & 0.302 & 0.371\end{array}$

*t-statistics based on robust standard errors in Column (4). Also included in all equations are: Rank in the alphabet and an indicator for female, and Column (4) also includes the number of full professors. 